
Cornell University Library

The temperature of the honeybee cluster

The fuU

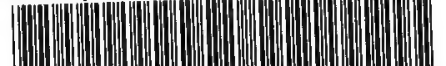

31924003445149

mant 


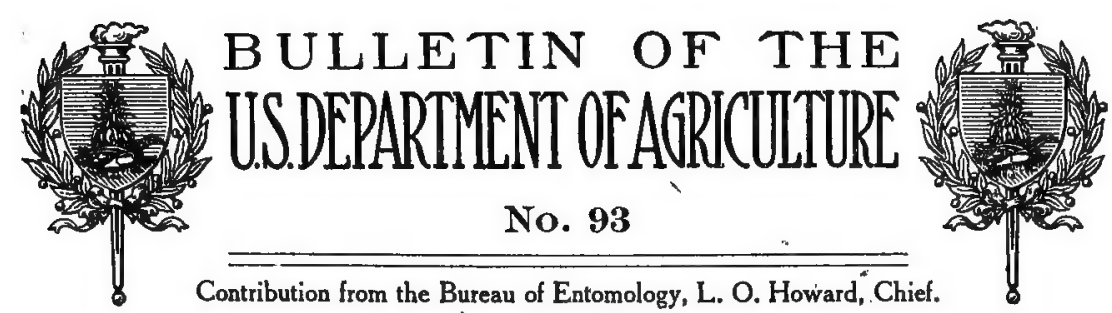
April 30, 1914.

\section{THE TEMPERATURE OF THE HONEYBEE CLUSTER IN WINTER.}

By E. F. (PhIllips, Ph. D., In Charge of Bee Culture Investigations, and George S. Demuth, Apicultural Assistant.

\section{INTRODUCTION.}

The care of bees in winter is one of the most perplexing problems confronting the beekeeper, especially in the North. This appears to be due chiefly to the fact that it is difficult to determine by direct observation the normal activities of the bee colony in winter, and consequently it is well-nigh impossible to determine what external conditions are most favorable except by the gross results of experience. Nor can we by a study of our wintering successes and failures determine definitely whether the same conditions of temperature and humidity are desirable throughout the entire winter.' On account, therefore, of the lack of accurate knowledge of the activities of bees in the winter season this problem has been taken up with the aid of certain special apparatus and equipment. This preliminary report is not to be considered as giving definite recommendations as to the care of bees in winter, but rather. is issued to make known to beekeepers some of the interesting results obtained in the first season's work on the behavior of the bees during the winter season.

American beekeepers lose thousands of dollars annually in winter from the actual death of colonies and even still more from those colonies that do not die, but which are reduced in numbers and vitality. The wintering problem is therefore a vitally important one. The factors influencing the welfare of the colony and the behavior of the bees are numerous and closely interrelated. Of the chief ones may be mentioned external temperature, food, ventilation, humidity, the condition of the colony at the beginning of winter, and various forms of irritation. In the present paper special emphasis is placed on heat production, by which is meant the responses of the bees of the cluster to the outer temperature and to changes in the outer temperature as manifested in the generation of heat by the bees.

NoTE.--This bulletin presents studies of bees as affected by temperature conditions during winter and is of special interest to beekeepers in the North.

$36157^{\circ}-$ Bull. $93-14$ 
A special reason for this emphasis in a preliminary paper is that all previous work on the temperature of the cluster in winter, of which there has been considerable, has failed to show definitely what the normal responses are. The data are often those of abnormal con-; ditions and are therefore misleading, making them almost valueless for purposes of application. One source of error which is to be found in all the records known to the authors is the use of the mercury thermometer, for, when such a thermometer is used, it is almost impossible to avoid disturbing the cluster at each reading so that it reacts abnormally. Furthermore, as the authors will attempt to show at a later time, disturbances of the colony may influence the temperature of the cluster for a considerable period, often more than one day. Usually no account has been taken of the necessary corrections to be made for the mercury thermometer.

Because of the errors in other work on the subject, due to the use of mercury thermometers, the thermometers chosen for the work here recorded are of another kind. Electrical thermometers are used by means of which readings can be made without approaching the hive, and the thermometers (couples) are of course permanently fastened in place. These are of the type known as thermocouples or thermal junctions and the readings are made by means of a potentiometer indicator and a sensitive galvanometer of the d'Arsonval type. The wires used in the thermocouples are copper and constantin (a copper-nickel alloy), giving an electromotive force of about $40 \mu \mathrm{V}$ per degree centigrade. A detailed description of the apparatus is impossible here, and it need only be stated that the method as used gives readings to an accuracy of $0.09^{\circ} \mathrm{F}$. $\left(0.05^{\circ} \mathrm{C}\right.$. $)$; the thermometers are practically instantaneous in their action-that is, show changes in temperature without a "lag"; the readings of many thermometers can be made consecutively on one carefully calibrated instrument, insuring uniformity, which is impossible in using many mercury thermometers; and, a point of importance in such work. the readings can be made at the rate of two a minute, which would be impossible with widely scattered instruments. In all, 161,617 temperature readings were made during the winter $1912-13$, and the work is being continued.

Part of the colonies are kept in a well-insulated room (ised as a "bee cellar") in the zoological laboratory of the University of Pennsylvania, Philadelphia, Pa., which can be kept at a temperature usually varying not over $2^{\circ} \mathrm{F}$., far more uniform than the ordinary bee cellar. Abundant ventilation is provided, and the room is completely darkened to avoid possible disturbance by light. The temperatures of the indoor colonies are read from an adjoining laboratory to eliminate the possible errors due to disturbance, and the room is entered rarely (about once a week on an average and, if possible, 
only after the day's records are made) and only when absolutely necessary. It is found that entering the constant-temperature room may under some conditions influence the behavior of the bees in a marked manner.

Other colonies are kept on the roof of the same laboratory, where they are left untouched from the beginning to the end of a series of readings. The wires of the thermometers are led to the room below through rubber tubes, and all the temperature readings are made at a distance, as is absolutely necessary to eliminate disturbance. Disturbances of outside colonies have also been found to influence their behavior in a pronounced manner, especially in cold weather.

By studying the temperature of various fixed points within each hive it has been found possible to use the temperature readings as a substitute for direct observations. After becoming familiar with the normal temperature and the temperatures incident to various activities one can tell the shape, location, and various activities of the cluster by a study of the temperature of different points within the hive and can, in fact, form an opinion as to the welfare of the colony. It has therefore been possible to follow closely the activities of each cluster without opening the hives and even without going near them.

\section{THE INFLUENCE OF EXTERNAL TEMPERATURE ON HEAT PRODUCTION.}

The colony (A) to be discussed under this heading was wintered out of doors (1912-13) on the roof, where the bees were free to fly whenever the weather permitted. It was in a 10-frame Langstroth hive, with the entrance reduced to $\frac{3}{8}$ inch deep and 8 inches wide, and was not packed or given additional protection. This hive contained 19 of the electrical thermometers-12 among the combs, 4 in the corners of the hive, and 3 on the bottom board. Readings were made hourly from 9 a. m. to 4 p. m. through the winter (Sept. 26 to Mar. 28), except Sundays and holidays, and at intervals additional readings were made every 15 minutes (or sometimes every 30 minutes) during the night $(5 \mathrm{p} . \mathrm{m}$. to $8.45 \mathrm{a} . \mathrm{m}$.) for periods of several days each. In all, 41,413 temperature records were made for colony $\mathrm{A}$.

The reaction of the cluster in heat production, as induced by changes in external temperature, is well shown by the records made from noon November 13 to 2 p. m., November 15 (1912), when readings were made hourly from 9 a. $\mathrm{m}$. to $4 \mathrm{p}$. $\mathrm{m}$. and every 15 minutes at night. From noon on November 13 the outside temperature dropped slowly until 6 a. m., November 15, and the weather was cloudy, so that the bees did not fly. It will be seen from the accompanying diagram (fig. 1) that at noon on the 13th the outside temperature was about $69.2^{\circ} \mathrm{F}$. and all the points within the hive were 


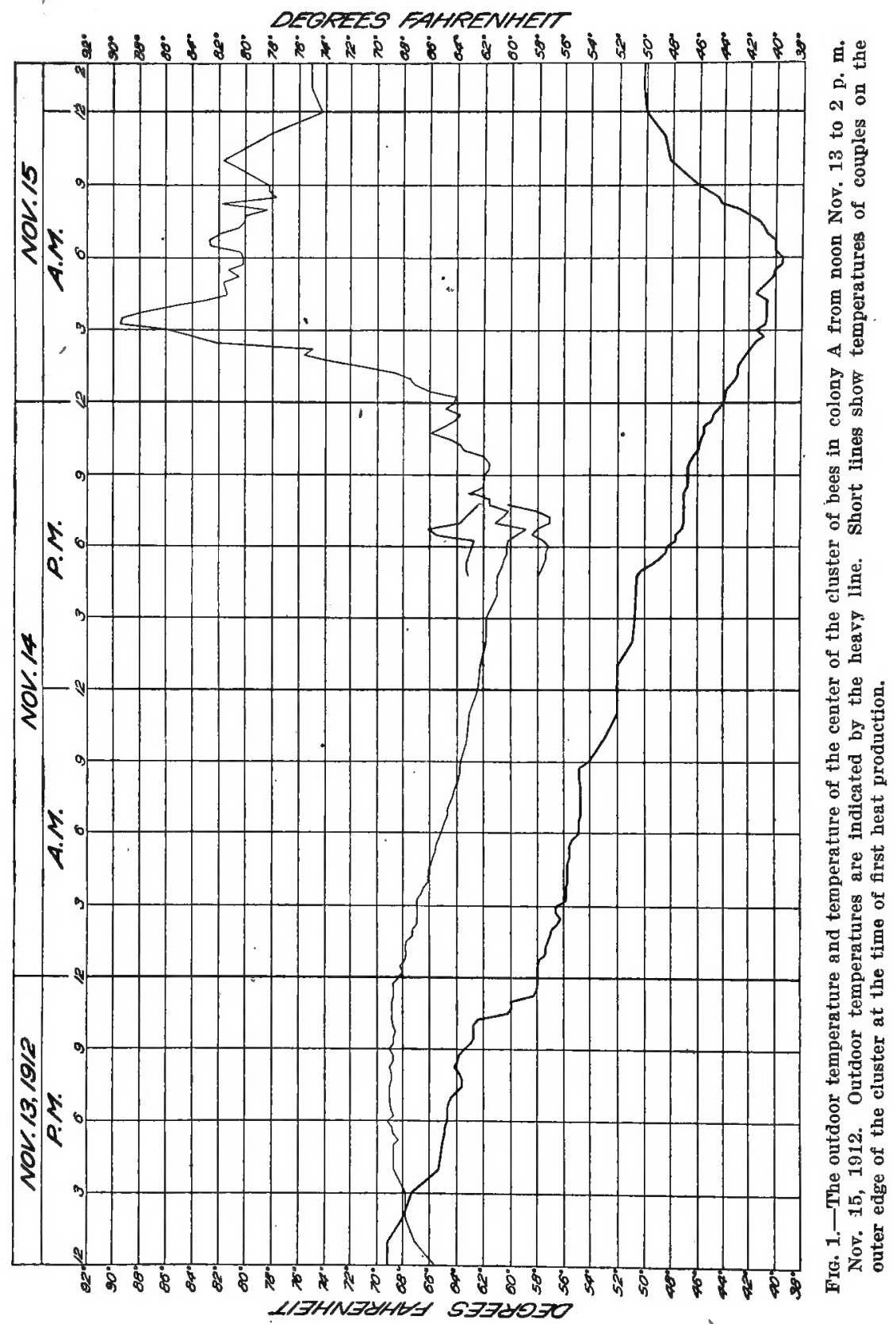


then cooler than the outside air, due to the fact that it took some time for the inside of the hive to warm up. At $4 \mathrm{p}$. m. the outside temperature had dropped to $65.3^{\circ} \mathrm{F}$., when it was lower than any of the points within the cluster, which had in the meantime become warmer. From this time until 6 p. m. the next day (14th) the temperature within the cluster gradually dropped as the outer air cooled, until the lowest one (No. 9) was 57 $7^{\circ}$ F. (Outside temperature, $48.2^{\circ} \mathrm{F}$.) The generation of heat began at $6.15 \mathrm{p}$. $\mathrm{m}$. at this point, which was to one side of the cluster, and is to be attributed to the movement of the bees in forming a definite cluster. At $6.30 \mathrm{p} . \mathrm{m}$. a rise in temperature was noticed on thermometer 19, at the other side of the cluster. Until $10.15 \mathrm{p}$. m. the changes in temperature are probably to be interpreted as incidental to the formation of a compact cluster, and from this time until the next day at the close of the series of readings the thermometers within the cluster showed a considerably higher temperature than the outer äir, or than the thermometers outside the cluster. The maximum in this series was reached at 3.15 a. m., November 15, when thermometer 12 in the center of the cluster registered over $89.4^{\circ} \mathrm{F}$.

After the coldest outside temperature was reached and the outer air began to get warmer $(6.15$ a. m., November 15$)$, there was a tendency for the cluster temperatures to drop. This is somewhat noticeable in the case now being discussed, and is more clearly seen in records obtained in other series. In general, after a period of cold, when the outside temperature begins to rise, the cluster temperatures drop slowly to meet the outside temperature. The generation of heat is reduced, or even discontinued, only to be increased when the outside temperature again drops, or when it gets high enough to induce greater activity, as in flight. It is found also by taking more frequent readings when the cluster temperature is above about $69^{\circ} \mathrm{F}$. that it is less constant than when it is below this temperature, indicating that at temperatures above this point the bees move about to some extent, while between $57^{\circ}$ and $69^{\circ}$ they are quiet, unless flight is desirable owing to a long confinement.

This series of readings is supported by numerous records taken on this and other colonies throughout the winter and, since all the observations tend to confirm what was first seen on the record presented here, the authors feel justified in presenting a definite statement of the reactions of the cluster to outside temperatures. - It may be added that a careful study of the records of previous investigators fails to show a similar statement on this subject. When a colony is without brood, if the bees do not fly and are not disturbed and if the temperature does not go too high, the bees generate practically no heat until the coolest point among the bees reaches a temperature of about $57^{\circ} \mathrm{F}$. At temperatures above $57^{\circ} \mathrm{F}$. a compact cluster is not formed, but the bees are widely distributed over the combs. At 
the lower critical temperature, which is for the present stated as $57^{\circ} \mathrm{F}$., the bees begin to form a compact cluster, and if the temperature of the air surrounding them continues to drop they begin to generate heat within the cluster, often reaching temperatures considerably higher than those at which they were formerly quiet and satisfied. It is evident, therefore, that the temperature within the cluster is far from being uniform in winter, as has been, in a sense, assumed among practical beekeepers. At the temperature at which other insects become less active (begin hibernation) the honeybee becomes more active and generates heat, in some cases until the temperature within the cluster is as high as that of the brood nest in summer. "To. sum up, when the temperature of a colony of undisturbed broodless bees is above $57^{\circ} \mathrm{F}$. and below about $69^{\circ} \mathrm{F}$. the bees are quiet and their temperature drifts with the outer temperature; at lower temperatures they form a compact cluster, and the temperature within it is raised by heat generated by the bees.

The, authors desire to state that while the lower critical point, $57^{\circ} \mathrm{F}$, appears rather well established, the observations up to the present do not justify too definite a statement concerning the upper limit of quiescence. It must be emphasized that these conditions do not apply when the colony has brood. The rearing of brood in winter causes a marked increase in heat production and constitutes a condition which may becomé one of the most disastrous that can befall a confined colony. This will be discussed at a later time.

When the heat production of the colony is explained, we are able to understand to some extent the divergence in the records obtained by other observers. It has, of course, long been known that bees generate heat, and it has been pointed out that during cold weather the temperature of the cluster is often higher than during warmer weather. While the temperatures previously recorded are in most cases abnormal, due to disturbance, the chief difficulty in understanding the phenomena which take place is due to insufficient observations. For example, if between noon November 13 and 2 p. m. November 15 only a half dozen temperature records had been made for the cluster (and perhaps without finding the warmest part of it) and the outside air, it would have been impossible to determine the limits of heat production. Most observers have been satisfied with a few observations, and seemingly everyone who has inserted a thermometer in a hive has felt called upon to publish the results, thereby only confusing the problem.

\section{THE EFFECT OF CONFINEMENT AND THE ACCUMULATION OF FECES.}

Before beginning a discussion of the effect of confinement and the accumulation of feces, it may be recalled that during the active summer season the length of life of worker bees is in a sense deter- 
mined by the work done by them, rather than by days or weeks. The greater the necessity for excessive activity the shorter the term of life. The authors believe that they have evidence to prove that this applies to the winter also, and this belief is entirely supported by the experience of beekeepers everywhere. That bees may come out of winter quarters strong in numbers and vitality it follows that the work to be done by the bees in the winter should be reduced to a minimum; and the winter problem, as thus interpreted, is therefore to find the conditions under which broodless bees do the least work. The work which broodless bees do in winter consists, so far as has been determined, solely in the production of heat or in activity incident to flying on warm days (if free to fly), and therefore the problem, so far as it is under the control of the beekeeper, is primarily to obviate the necessity for the production of heat. If brood is reared the work of the bees is necessarily enormously increased, and their vitality is correspondingly decreased. So far as evidence is available in this work, the colony is not fully recompensed for this expenditure of energy by an increase in the strength of the colony by bees thus reared.

The colonies ${ }^{1}$ to be discussed under this heading (Nos. 1 and 3 ) were wintered in the constant-temperature room in special 6-frame hives (to economize space and concentrate the colony so that fewer thermometers would be required) with full entrances and were not propolized or sealed at the top. During the regular series of readings the room was kept at a temperature which rarely dropped below $40^{\circ} \mathrm{F}$. or went above $45^{\circ} \mathrm{F}$, and the average temperature from October 14 to March 6 was $42.67^{\circ} \mathrm{F}$. This temperature was chosen as being nearly the one usually considered best by beekeepers. The foods given these colonies were stored in the combs, just as placed by the bees. There was some pollen available in colony No.' 1. (Fig. 2.)

According to what has been said in the previous section, we should expect bees at such a temperature to maintain a compact cluster and to generate some heat at all times. This was actually the case, the temperature of the interior of the clusters dropping below $64^{\circ} \mathrm{F}$. only a few times in either colony.

Colony No. 1, on honey stores, was in the constant-temperature room from October 12, 1912, to March 24, 1913, or 163 days. $^{2}$ It

1 In order that the young bees might all get a flight before the winter confinement, the two colonies here discussed were placed in the constant-temperature room after the brood had been removed. They were kept here several days, removed for a flight, and then returned to the room for the regular series. The significance of this manipulation must be reserved for a later discussion. This explanation is made to show how it was possible to put these colonies in the room so early in a climate as mild as that at Philadelphia. The object was, of course, to increase the time available for observation. Bees are usually not wintered in cellars in climates as mild as that of Philadelphia.

$\stackrel{2}{2}$ all, 24,077 temperature records were made for this colony. 
was then removed for a flight and put back the same evening, where it remained until March 28. From March 7 at 9 a. m. until March 28 at 4 p. m. readings were made on this colony every 15 minutes night and day, with the exception of the period between 9 a. $\mathrm{m}$. and $7 \mathrm{p} . \mathrm{m}$. on the $24 \mathrm{th}$, when it was out of doors. During this period of three weeks the temperature of the room was changed slowly, being raised as high as $64^{\circ} \mathrm{F}$. and cooled to $13^{\circ} \mathrm{F}$.

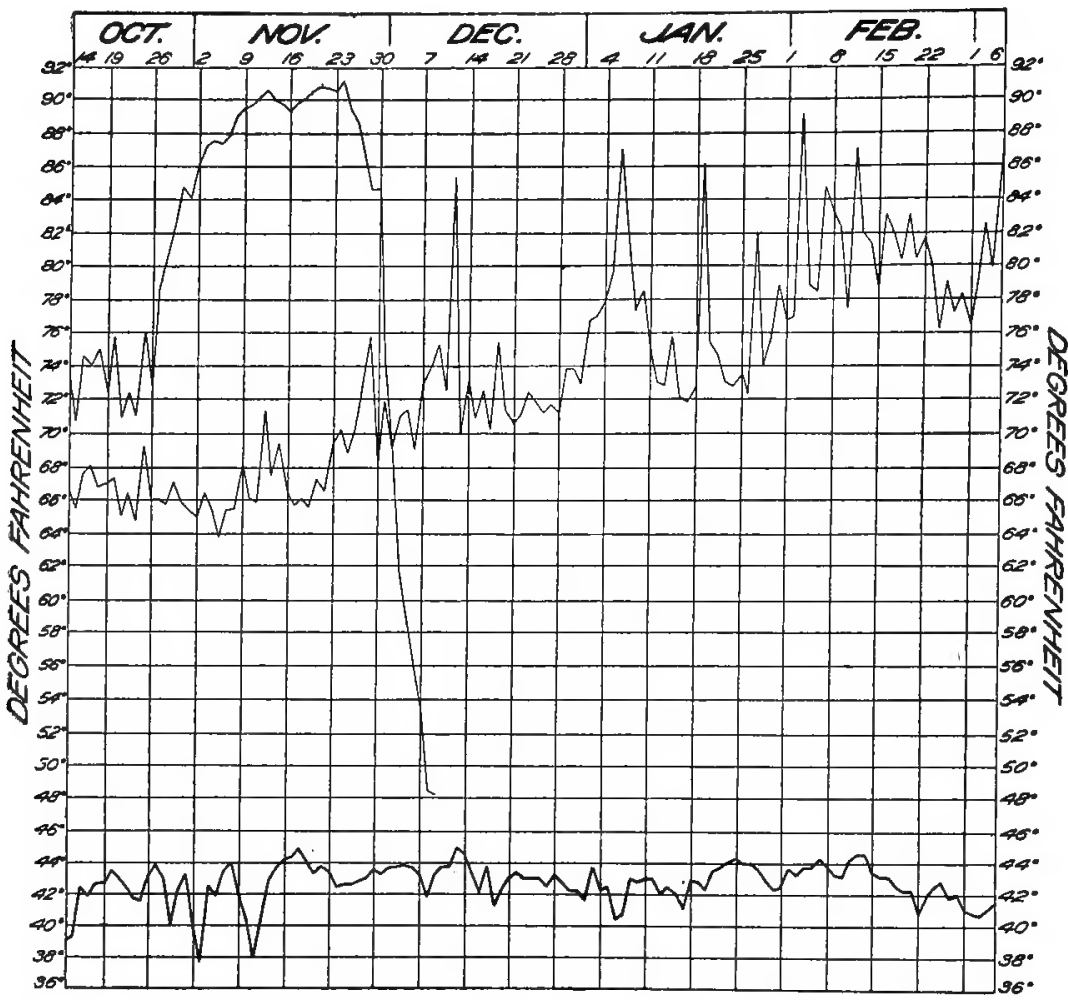

FIG. 2.-Average daily temperatures of the center of the cluster of bees in colonies 1 and 3 and room temperatures, Oct, 14, 1912, to Mar. 6, 1913. Taken from readings made hourly from 9 a. $\mathrm{m}$. to $4 \mathrm{p} . \mathrm{m}$. The room temperatures are indicated by the heavg line.

When this colony was first placed in the room for the regular series of readings, after a preliminary confinement, October 12 (the readings were begun Monday, Oct. 14), it maintained a cluster temperature which usually lay between $64^{\circ}$ and $68^{\circ} \mathrm{F}$., the daily average temperature departing from these rather narrow limits only four times up to November 22. The average temperature is $66.5^{\circ} \mathrm{F}$. During the first five weeks the temperature of the room was less regular than later (due to faulty working of the regulating apparatus), and this doubtless accounts for some irregularities in the cluster temperature. At first the three thermometers in the cluster $(1,2$, and 5 ) gave tem- 
perature readings quite close together, while thermometer 6 , which was near the cluster, gave readings intermediate between the three thermometers of the cluster and the four others in the hive, farther from the cluster. After November 22 the records of the thermometers in the cluster were more widely separated and the temperature of the center of the cluster (shown on thermometer 5) tended to rise gradually. It varied constantly, but by December 7 and from then until the end of the month, it averaged between $69^{\circ}$ and $75^{\circ} \mathrm{F}$. On November 29 and December 12 the cluster temperature rose to over $88^{\circ} \mathrm{F}$. From the 1st of January until March 6, which ended the regular series of readings, the cluster temperature became more and more irregular, and on January 20 the cluster moved (probably to accommodate itself to the stores) until thermometer 2 was nearer the center and showed a higher temperature than thermometer 5. The size of the cluster was gradually decreased by the death of bees, and all the thermometers except 2 and 6 show a gradual decrease in temperature until finally, from about February 25 to March 6, they are all low and of nearly equal temperature. The two thermometers giving high readings continued to show in general a higher and higher average temperature and to become more irregular (except from February 15 to March 1), the periods of increased heat becoming more frequent. There was absolutely no regularity in these intervals. After February 1 the temperature of the cluster varied between $75^{\circ}$ and $91^{\circ} \mathrm{F}$., the average from February 1 being $85.4^{\circ} \mathrm{F}$.

On March 6 all colonies in the constant-temperature room except two were removed. The colony described above (No. 1) and one other (No. 12), not to be described at present, were left. On March 7 at $9 \mathrm{a}$. m. the temperature of the room stood at $42^{\circ} \mathrm{F}$., and the temperature of the interior of the cluster was about $84^{\circ} \mathrm{F}$. The brine which cooled the room was then shut off and the temperature of the room rose very slowly and regularly, until on March 11 at 8.45 a. $\mathrm{m}$. it was $64^{\circ} \mathrm{F}$. For the first day the temperature of the cluster was slightly variable, and at $10.45 \mathrm{p}$. m. thermometer 6 , which had been cooler than thermometer 2 , showed a rise in temperature (probably due to a shifting of the cluster), and from then on to the 24th they were nearly of the same temperature at all times. On March 8, at 3 a. m., thermometer 2 rose to $87^{\circ} \mathrm{F}$. (room temperature, $48.5^{\circ}$ F.), having previously shown a cooling. The cluster temperature then dropped slightly, showing relatively little variation until at 4.15 p. m., March 9, it stood at $77.3^{\circ}$ F. (room temperature, $55.7^{\circ}$ F.). As the room temperature continued to rise, the cluster temperature increased still more rapidly, until at 8.15 a. m., March 11 , it reached $93^{\circ} \mathrm{F}$. (room temperature, $64.2^{\circ}$ F.). A little brine was now turned on, sufficient to lower the temperature gradually to $58^{\circ} \mathrm{F}$. at 9 a. m., March 12 , and it again rose to $63.3^{\circ} \mathrm{F}$. at $5.45 \mathrm{p}$. m., 
March 15. During this period the cluster temperature followed the room temperature, but remained constantly over $20^{\circ}$ warmer. The room was again cooled slowly, and the cluster temperature dropped until on March 16, at 3 p. m., the room was $49^{\circ} \mathrm{F}$. and the cluster $77.5^{\circ} \mathrm{F}$. As the room continued to cool, the cluster temperature increased, the bees responding to the colder temperature, until at 4.15 a. m., March 17 , the room was $48^{\circ} \mathrm{F}$. and the eluster $88^{\circ} \mathrm{F}$. The room then gradually warmed, and again the temperature of the cluster dropped and then again rose with the room temperature, remaining always over $20^{\circ}$ warmer. At $6.45 \mathrm{p}$. m., March 19 , the brine was turned on full and the room cooled rapidly, reaching the minimum of $13^{\circ} \mathrm{F}$. at 9 p. m., March 20. At no time, however, did any of the thermometers in the hive record a temperature below $33^{\circ} \mathrm{F}$. Here it remained constant within $0.1^{\circ} \mathrm{F}$. for about six hours, during which time the cluster temperature varied between $86.5^{\circ}$ and $89.5^{\circ} \mathrm{F}$. (a difference between the room and the cluster temperatures of $73^{\circ}$ to $76^{\circ} \mathrm{F}$.). The brine was now shut off and the room again warmed until 9 a. m., March 24 , when it reached a temperature of $44.5^{\circ} \mathrm{F}$. During this warming the cluster cooled until at the close it was varying between $72^{\circ}$ and $79^{\circ} \mathrm{F}$.

As stated above, the colony was now (9 a. m., March 24) removed for a flight and put back the same day at $7 \mathrm{p} . \mathrm{m}$. In the meantime the room was cooled to $33^{\circ} \mathrm{F}$. When the bees were put back into the room the temperature of the entire inside of the hive showed great variation and naturally an increase due to the warming up while out of doors and to the activities of a good flight. The points outside the cluster dropped rapidly, but it was midnight, March 25 (31 hours), before the curves of temperature again appeared normal. The room was slowly warmed to $63.2^{\circ} \mathrm{F}$. at 6.30 p. m., March 26, and then slightly cooled to $54^{\circ} \mathrm{F}$. at 6 a. m., March 27 , and again warmed to $58.5^{\circ} \mathrm{F}$. at the close of the series, $4 \mathrm{p}$. m., March 28 . After the flight the temperature of the cluster never dropped below $89.5^{\circ} \mathrm{F}$., and the highest temperature reached was over $95^{\circ} \mathrm{F}$. (soon after the flight). Thermometer 6 remained high, but thermometer 2 , which had previously been high, now approached the other thermometers, probably due to a rapid loss of bees and to a decrease in the number of bees during the flight. It must be recalled that these bees had been confined for an abnormally long time and were subjected to treatment which is at least unusual. After this colony was taken from the room for the last time it was found that thermometer 6 was over a patch of larvæ, and, estimating as accurately as possible, the eggs from which these hatched must have been laid at the time when the room was coldest (March 20-21) and when the cluster temperature was at its highest point. There had been no brood previously, according to the temperature records as compared with those 
of this colony earlier and with those of other colonies, nor was there much evidence of increased heat production due to the presence of brood until after the flight. Probably no extra heat was produced for the eggs, and possibly the hatching of the eggs was somewhat delayed by the low outer temperature. The effects on the cluster temperature which might be expected from a flight, in relieving the accumulation of feces, were not observed, because brood rearing had been begun.

Colony No. 3 was placed in the constant-temperature room October 12, 1912, after a good flight, and readings were begun on Monday, the 14th. In all, 2,165 temperature records were made on Colony 3. The stores provided this colony consisted of honeydew honey, which was gathered in the department apiary and which, since it granulated almost at once, had been removed by melting up the combs which contained it. After this operation it remained liquid. During the summer of 1912 some of this honeydew honey was fed to a colony in the open, during a dearth of nectar, and was stored in new combs above the brood chamber, in which no cells of pollen were to be found. After the second storing the honeydew honey was clear, well ripened, and did not granulate. This colony was also in a 6-frame hive, as previously described, and contained five thermometers (Nos. 14-18) among the combs. It is of course well known to beekeepers that honeydew honey is not a good food for winter.

When this colony was first put into the constant-temperature room it behaved much as did Colony No. 1 , except that the temperature varied between $69^{\circ}$ and $78.7^{\circ} \mathrm{F}$. for the first week, being slightly higher and more variable than that of Colony No. 1 . The second week it remained much the same, the temperature, however, varying between $69^{\circ}$ and $80^{\circ} \mathrm{F}$. From this time on the temperature of the center of the cluster rose rapidly, never dropping below $79^{\circ} \mathrm{F}$. from October 29 almost to the close of the readings. After November 4 the temperature remained above $86^{\circ} \mathrm{F}$., and after November 11 it dropped below $89^{\circ} \mathrm{F}$. only twice until the end. Thermometer 17 at first read about $4^{\circ}$ below thermometer 14, but after November 11 they were, close together until November 25, when thermometer 17 began to cool rapidly, due to loss of bees, and after November 30 thermometer 14 cooled rapidly until, on December 9 , it showed that no more bees remained alive. From December 2 to 7 , inclusive, there was little heat generated, due to the scarcity of bees. It is of interest to observe the records of thermometer 16 , near the cluster, but usually outside of it. It at first showed a temperature but little higher than the two thermometers away from the cluster, but on October 31 it began to rise until, on November 12 , it reached $80.5^{\circ} \mathrm{F}$., when it was doubtless covered by the bees. Even the two thermometers (15 and 18) clear to the back of the hive rose until, on November 13, they 
recorded $61.5^{\circ} \mathrm{F}$. These thermometers showed about the same temperatures for about 10 days, and then these two and thermometer 16 showed a cooling, since the bees were dying so fast that there were no longer enough to warm up these thermometers away from the center of activity. It was to be expected that this colony would die, and the experiment was performed to learn the phenomena incident to the loss.

Before summing up the results of these two colonies, Nos. 1 and 3, it may be stated that, so far as the evidence here presented is concerned, the results as far as here discussed are confirmed by records from 10 other colonies kept in the constant-temperature room, but fed other foods and otherwise different. There is in all of the records no evidence which the authors can interpret as at all contrary to the views here stated. A discussion of these other colonies is reserved.

It is evident from the behavior of colony No. 1 that at least one factor entered which gradually caused the bees in the cluster to generate more and more heat until at the beginning of the special series, March 7, the cluster temperature was about $20^{\circ}$ warmer than it was at the same room temperature at the beginning of the confinement. It is also seen that during the special series, March 7-24, the cluster temperature always remained at least $20^{\circ}$ above the room temperature, whereas from the discussion of bees unconfined (Colony A) we might expect them to cease heat generation when above the lower critical temperature $\left(57^{\circ} \mathrm{F}\right.$.). In the case of colony 3 , fed on honeydew honey stores, the factor which caused more heat to be produced evidently increased much more rapidly. As stated previously, honeydew honey is a poor food for winter and is so recognized. It contains the same sugars as honey, but contains in addition a considerable amount of dextrin, the particular lot fed to colony 3 containing 4.55 per cent while good honeys contain only a fraction of 1 per cent. From the evidence at hand it appears that dextrin can not be digested by bees and, whether or not this is the explanation, honeydew honey causes a rapid accumulation of feces which usually results in the condition known as dysentery, in bad cases of which the feces are voided in the hive. In the case of colony 3 the whole hive inside and out, as well as the frames and combs, were spotted badly, the inside of the hive being practically covered. Even with fine honey stores such a spotting is usually noticed after a prolonged confinement, especially in severe weather (or during brood rearing). It therefore appears that the accumulation of feces acts as an irritant, causing the bees to become more active and consequently (see later section) to maintain a higher temperature. We are therefore justified in believing that the cause of poor wintering on honeydew honey is due to excessive activity, resulting in the bees wearing themselves out and ultimately in the death of the colony. 
In the case of colonies on good stores (e. g., colony 1) the feces accumulate more slowly and the excess activity is not so marked and is induced more gradually. The accumulation of feces due to confinement causes increased activity and this in turn is the cause of excessive heat production, resulting in a reduction in the vitality of the bees.

It therefore follows that excessive activity causes the consumption of more food, resulting in turn in more feces', so that colonies on poor stores are traveling in a vicious circle, which, if the feces can not be discharged, results in the death of the colony. In the work here recorded no attention was paid to the theory that dysentery is due to an infection, since there is nothing in the observations made that lends any support to that idea. If there is more than one kind of dysentery, as has been held, then the observations here recorded must be considered as applying only to the type which can be induced at will in any confined colony by giving poor food and which, as has been long recognized, can be relieved at once by an opportunity for flight.

While the activity of the cluster is greater at some times than at others, there are not, as has been held, regular intervals of activity. at which the colony rouses itself to take food. At no time is a colony kept at a room temperature of $45^{\circ} \mathrm{F}$. or less in a condition which can be characterized as inactive. Presumably the reported "interrals of activity" have occurred when the colony made a noise due to disturbance by the beekeeper.

The bees in colony 3 were compelled to. work constantly to maintain so high a cluster temperature. In fact, they did more work than colonies wintered in the open air. Keeping these bees in a cellar protected them from low outside temperatures, but the lack of opportunity for a normal ejection of feces caused a condition more serious than extreme cold weather. We seem to have here an explanation of the fact, often observed by beekeepers, that some colonies wintered in the cellar are in worse condition in the spring than colonies that are exposed to severe cold. Poor food is evidently a more serious handicap than low temperature.

\section{METHODS OF HEAT PRODUCTION AND CONSERVATION.}

A colony of bees in cold weather forms a compact, approximately spherical cluster, but this cluster is not, as is usually believed, uniformly compact. In order to study the formation of the cluster and as an aid to interpreting the temperature records in terms of action, a colony (C) was placed out of doors in a narrow hive with doubleglass sides and top, and the stores were so arranged that the only space available for the formation of the cluster was next to the glass on one side, where it could be kept under direct observation. Since 
the bees did not have room for a spherical cluster, they formed a ring on the glass. Thermometers were then placed close together in the outside space, so that the temperatures of various points could be determined as desired. This hive was on the roof, and, while one person watched the bees, constant communication could be kept up with the person reading the temperatures in the room below by means of a telephone, arranged so that the hands of both observers were free. This colony was of course in the light, but the normal cluster was nevertheless observed. It was disturbed as little as possible.

The nearly spherical cluster of bees consists, between the combs and sometimes above or below them, of an outer shell of bees close together with their heads toward the center. This ring may be several layers thick. The position with the heads inward is typical, except when condensed moisture drops on the cluster as it often does in cool weather, when the bees at the top turn so that their heads are upward. The bees in this outer shell are quiet except for an occasional shifting of position. Inside this rather definite shell the bees between the combs are not so close together nor are they headed in any one way. Considerable movement, such as walking, moving the abdomen from side to side, and rapid fanning of the wings, takes place inside the sphere and when a bee becomes unusually active the adjoining bees move away, leaving an open space in which it can move freely. Two bees may often be seen tugging at each other. In addition to the bees between the combs, placed as above described, others are in the empty cells of the comb on which the cluster is always formed, always with their heads in. A verification of these statements is contained in the following observations, and the experiment may easily be repeated by anyone. For the purpose of obtaining a colony without combs for another experiment, a hive was opened December 15, 1913, while the outside temperature was low enough to cause the formation of a compact cluster. When the combs were separated the circle of bees in the shell was clearly observed. When a comb from the center of the cluster was shaken the active bees in the center of the circle dropped off readily, and those in the outer shell which were somewhat sluggish were removed with more difficulty. After this was done those occupying empty cells in the center of the sphere backed out of the cells and were shaken off. Finally those occupying cells in the border of the sphere backed out, showing a well-marked circle on the combs. Evidently the bees in the shell, whether in the cells or between the combs, are less active than those in the interior of the cluster. Naturally such a manipulation as this is not to be recommended, except for purposes of demonstration.

It is clear from observations previously recorded that the highest temperatures are those of points in the center of this shell, and this is 
to be expected, as the heat is generated here. The outer shell constitutes an ideal insulator for the conservation of the heat, since the bees arranged so close together form small dead air spaces in their interlacing hairs, especially those of the thorax, and afford still more insulation with their bodies. The abdomens of the bees in the outer row are practically separate one from another, and must often be exposed to severe cold. That this method of conserving heat is effective is shown by observations on undisturbed colonies out of doors. For example, on January 14, 1914, there was at 9 a. m. a difference of $68^{\circ} \mathrm{F}$. between thermometers 14 (center of the sphere) and 16 (outside the cluster) of Colony $\mathrm{D}$, which were less than $4 \frac{1}{2}$ inches apart on the same level in the same space between combs, and a difference of $75^{\circ} \mathrm{F}$. between this couple and the bottom board 44 inches below it. What this difference might sometimes be in colder climates may be imagined. Examples of this kind might be multiplied indefinitely from the records of these experiments.

The source of the heat of the cluster must, of course, be the oxidation of the food consumed by the bees. The bee is classed as a cold-blooded animal in that the temperature of the individual bee is practically that of the surrounding medium. There is obviously, from the records just given, no internal regulation of the temperature of the body such as is found in birds and mammals, for the temperature of a broodless cluster varies greatly. From the observations made on the various colonies, especially Colony $\mathrm{C}$, it is clear that heat for the warming of the cluster is produced by muscular activity. While, of course, some heat is doubtless liberated by other life processes, this is practically negligible when bees are quiet, as in Colony $\mathbf{A}$ when above $57^{\circ} \mathrm{F}$. That higher temperatures may be produced, greatly increased muscular activity is required, and in Colony $\mathrm{C}$ in cold weather bees in the center of the shell of insulating bees were seen fanning vigorously and executing other movements, such as shaking and rapid respiration. We thus have the paradoxical condition that bees fan to heat the cluster in winter as well as to cool the hive in summer. Observations of this kind were repeated beyond number, and this theory of the method of heat production is entirely supported by the repeated observation of a humming noise from the cluster during cold weather.

A few details of the observations on Colony $\mathrm{C}$ may be of interest. For example, one bee was observed fanning vigorously for $7 \frac{1}{2}$ minutes (9.53 to $10.00 \frac{1}{2}$ a. m., Jan. 23) while the other bees kept a space cleared for it. The temperature of the nearest thermometer rose $\frac{1}{2}^{\circ} \mathrm{F}$. during this time. At 9.52 this thermometer was almost a degree cooler than at the time of greatest heat during the fanning. The rapidity of fanning of the wings varied, and toward the end of the time it became so slow that the outline of the wings was distinguishable. After the 
excessive activity this bee stood in the same place for a time. Rapid respiration may play a more important part in heat production than at first appears. One bee was observed to breathe 21 times in 14 seconds and then cease the rapid respiration. On other occasions 50 or more bees would begin shaking their bodies from side to side.

It has been shown in earlier sections that feces in the rectum cause irritation, which induces increased activity and causes greater heat production. It has also been found that other kinds of irritation bring about the same result, but a discussion of these points can not be undertaken here. It is at least evident from the records obtained in this work that colonies of bees in winter, either in cellars or out of doors, should be disturbed as little as possible. This appears to apply especially to cold weather out of doors or in the cellar, especially after the colony has been confined for some time.

The facts mentioned concerning the ability of the bees to conserve the heat generated will perhaps raise the question as to the temperature of the hive outside the cluster in cold weather, when the cluster is compact. In the case of Colony $A$ the temperature of the hive outside the cluster was often practically as low as the outside temperature. This colony was not packed and had a rather large entrance. If the cluster forms such an efficient insulator in itself it might be presumed that packing about the hive is of little value and that it might.even be harmful, in that it would not serve to conserve heat and would prevent the heat from the sun from penetrating to the cluster. This line of reasoning, however, does not follow, and in any case it is unsafe to speculate about these things without more facts. The effects of various forms of packing are being studied.

In closing it may be desirable again to state that too hasty conclusions must not be drawn from the facts here presented. For example, the records on heat production might be interpreted as indicating the desirability of a cellar temperature higher than beekeepers usually believe to be best. Experiments to test such a theory are now being carried on, and it is found that a broad statement as to the best cellar temperature can not yet be given. Under most conditions colonies can not be brought to the critical temperature, $57^{\circ} \mathrm{F}$, without disturbance. It is hoped that more work will throw some muchneeded light on this important subject.

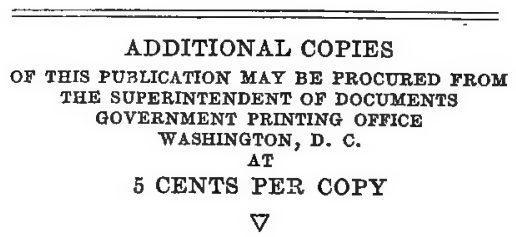





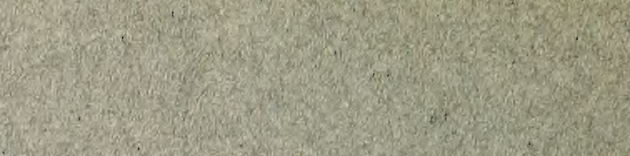

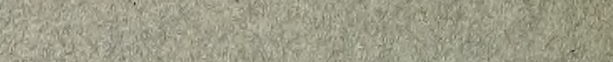

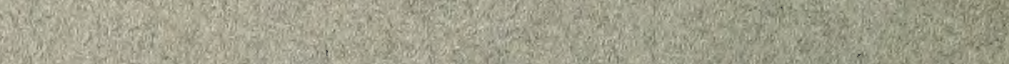
4. S.

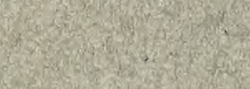

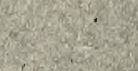

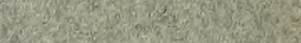

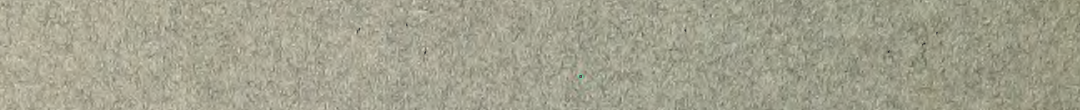
on: 350

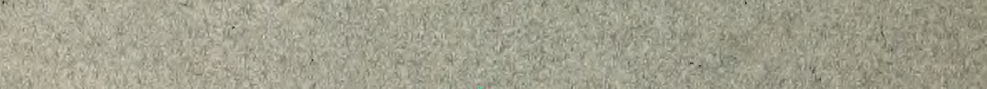

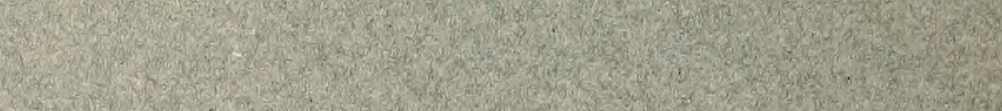


(1)

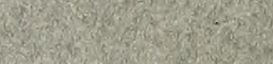

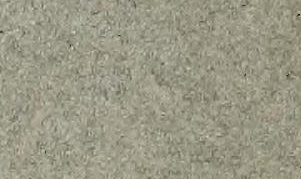
Shat a. satein 20. 